\title{
Advances in Silicon Carbide Electronics
}

\section{J.C. Zolper and M. Skowronski, Guest Editors}

\begin{abstract}
After substantial investment in research and development over the last decade, silicon carbide materials and devices are coming of age. The concerted efforts that made this possible have resulted in breakthroughs in our understanding of materials issues such as compensation mechanisms in high-purity crystals, dislocation properties, and the formation of $\mathrm{SiC} / \mathrm{SiO}_{2}$ interfaces, as well as device design and processing. The progress accomplished over the last eight years in $\mathrm{SiC}$-based electronic materials is summarized in this issue of MRS Bulletin.
\end{abstract}

Keywords: silicon carbide, electronic materials, high-frequency power electronics, reliability.

Since the 1950s, we have been living in the "silicon world," with silicon as the foundation of the electronics era. At the beginning of the 21st century, the electronics industry is still dominated by silicon and is likely to remain so for at least another decade. No other semiconducting material can compete with silicon in terms of low defect densities, long minority carrier lifetimes, perfection of the semiconductor/ dielectric interface, or doping control. Other materials-for example, GaAs and its alloys-only fill niche applications such as light-emission, where silicon is at a disadvantage due to its indirect bandgap. An indirect bandgap allows for the recombination of electrons and holes only with the participation of a phonon, a four-particle process that is inherently less likely than the three-particle process possible in a directbandgap semiconductor.

This situation could soon change in highvoltage switching and high-frequency power devices. The new material that can replace well-established silicon is hexagonal silicon carbide, a related semiconductor, which is the focus of this issue of MRS Bulletin. $\mathrm{SiC}$ technology is clearly not nearly as mature as that of silicon, and it is still more expensive than silicon, but its inherently superior properties, such as high breakdown field and thermal conductivity, provide a strong driving force for its development and implementation. Materials advances have reduced defect densities and improved the interface properties of $\mathrm{SiC}$, and improvements in design and processing are bringing it to the fore as a serious competitor in electronics applications. For more background on $\mathrm{SiC}$ technology, see the article by Dhar in this issue.

Silicon carbide was also the theme of the March 1997 issue of MRS Bulletin, eight years ago. At that time, the only commercially available $\mathrm{SiC}$ products were conducting wafers (with diameters of up to $13 / 8$ in.) and blue light-emitting diodes (LEDs). These were, however, the last days of $\mathrm{SiC}$ based LEDs. They were replaced by more efficient devices based on direct-bandgap GaN and other Group III nitrides. Surprisingly, however, the explosive growth of the nitride LED market and full-color displays had a positive impact on the development of silicon carbide technology. Single-crystal $\mathrm{SiC}$ wafers formed an ideal template for nitride epitaxy due to good lattice match and higher thermal conductivity than any other available wafer material, and a stable, sizeable market for silicon carbide wafers was created. This provided support and incentive for the continued development of silicon carbide growth technology. Today, there are six companies-Cree Inc., II-VI Inc., Intrinsic Semiconductor, Dow Corning Compound Semiconductor Solutions, SiCrystal AG, Sixon, and Norstel ABbased in the United States, Europe, and Japan that offer single-crystal $\mathrm{SiC}$ substrates. The recent production standard-namely, 2-in.-diameter wafers-is being replaced by 3 -in.-diameter wafers, with 100-mmdiameter wafers (4-in.-diameter) in development. Volume production has lowered the cost of a wafer unit area by a factor of 3 , compared with 1997 (\$1,400 for a 13/8 in. wafer in 1997 versus $\$ 2,400$ for a 3-in.diameter wafer today).

Although much improved, the quality of silicon carbide materials remains an active area of research and development. In 1997, the predominant material concern was the so-called micropipe defect (Figure 1), which seemed unique to silicon carbide grown by physical vapor transport. Micropipes are tubular voids with diameters between $0.1 \mu \mathrm{m}$ and $1.0 \mu \mathrm{m}$ that can extend through the entire $\mathrm{SiC}$ crystal. Since then, several different nucleation mechanisms for micropipes have been identified, such as nucleation on second-phase inclusions in $\mathrm{SiC}$ crystals $^{1}$ and coalescence of elementary screw dislocations. ${ }^{2}$ As the result, the micropipe densities have been reduced significantly. They still represent a yield issue for large-area devices, but do not constitute a fundamental, insurmountable problem.

Besides micropipes, considerable effort has been focused in the last three years on basal-plane dislocations. These defects are responsible for the degradation of $\mathrm{SiC} \mathrm{bi-}$ polar devices, most notably high-voltage pin diodes $^{3}$ (see the articles by Chow and by $\mathrm{Ha}$ and Bergman in this issue). A typical dislocation density in commercial crystals is in the $10^{3}-10^{4} \mathrm{~cm}^{-2}$ range, but an exciting breakthrough in material quality was announced just several months ago. A research group at Toyota Central R\&D Laboratories and DENSO Corp. reported the growth of $\mathrm{SiC}$ boules (2-in.-diameter by 1-in.-thick

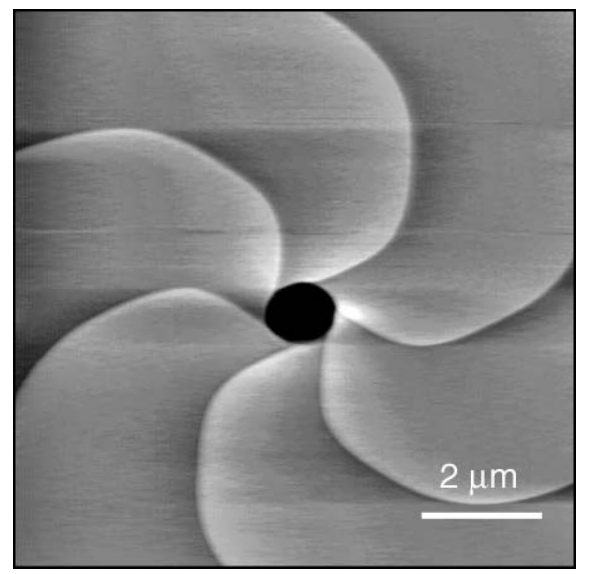

Figure 1. Atomic force microscopy image of a micropipe defect intersecting the SiC growth surface. The step height in this image is $1.5 \mathrm{~nm}$ and corresponds to one unit cell of $6 \mathrm{H}-\mathrm{SiC}$. The black area in the middle of the image is an open core of a superscrew dislocation with a Burgers vector of $7 \mathrm{c}$ (where $\mathrm{c}$ is the lattice constant along the [0001] axis). Courtesy of G.S. Rohrer. 
bulk crystal) with exceptionally low defect densities using a novel "repeated $a$-face" approach. ${ }^{4}$ This method takes advantage of the tendency of extended defects in hexagonal silicon carbide to propagate only along specific crystallographic directions. A sequence of growth experiments using seeds cut along the [1120] direction, followed by growth along the perpendicular [0001] axis, tends to lower defect densities. Two-inchdiameter wafers had total defect densities in the low hundreds per square centimeter, 1-2 orders of magnitude lower than previously reported. This development could lead to the growth of dislocation-free $\mathrm{SiC}$ crystals and epilayers, a distinction reserved only to silicon so far. "Dislocation-free" has been used to refer to crystals with dislocation densities below $1 / \mathrm{cm}^{2}$; the lowest dislocation density reported for $\mathrm{SiC}$ is $75 / \mathrm{cm}^{2}$.

Another important accomplishment in bulk growth is the availability of highresistivity substrates for low-loss, highfrequency devices (see the article by Sumakeris et al. in this issue). The original approach to fabricating such material was intentional compensation of shallow residual impurities (with electron binding energies on the order of $k T$ at room temperature) by deep electron levels induced by vanadium doping. ${ }^{5}$ This approach reliably produced crystals with the Fermi level pinned by deep vanadium levels far from the conduction- and valence-band edges. However, a high density of vanadium centers resulted in the trapping of reduction of the transconductance during operation of $\mathrm{SiC}$ metal semiconductor fieldeffect transistors (MESFETs). Such drift of the rf performance is known as current collapse. ${ }^{6}$

An alternative approach was the development of high-purity material, which relies on compensation due to deep levels associated with native point defects. ${ }^{7}$ One of the most attractive characteristics of silicon carbide is the high breakdown field (3.5 MV/cm, six times higher than that of silicon; see Table I) due to its strong bonds and large bandgap. This, together with the availability of low-defect-density material, electrons in the substrate and a gradual

makes silicon carbide ideally suited for next-generation high-voltage switching devices (discussed by Zhao and by Chow in this issue). The first such device, namely, the Schottky diode, became commercially available in 2001. These devices, rated for 300-1200 V, are competing with silicon pin diodes for applications in power supplies of such ubiquitous products as personal computers and industrial electric motor controls.

SiC-based diodes are still significantly more expensive than their silicon counterparts, but they offer one considerable advantage: better energy efficiency. Every time the voltage reverses sign, the injected minority carriers in a silicon bipolar diode cause the current to flow until they are eliminated by recombination. This "current overshoot" is a major part of efficiency loss. Enter silicon carbide: the much higher energy barrier in SiC Schottky structures makes it possible to replace the $\mathrm{Si}$ bipolar device with a $\mathrm{SiC}$ unipolar metal-semiconductor junction. Since there is no minority carrier injection, the current overshoot is eliminated, and the switching losses are reduced by about an order of magnitude. At times of abundant cheap energy, this would not be a major consideration, but in the era of the Kyoto Protocol and the impact of greenhouse gas on the planet's climate, it represents a definite advantage.

For blocking voltages in excess of about $3 \mathrm{kV}$, the Schottky diode ON-state resistance becomes prohibitively high, and for such applications, the $\mathrm{SiC}$ pin diode appears to be the rectifier of choice. The already mentioned high breakdown field of $\mathrm{SiC}$ allows one to make these devices with blocking layers having one-sixth of the thickness of their silicon counterpart with the same nominal blocking voltage. This results in much lower ON-state losses and increased energy efficiency. The more advanced highvoltage switching devices currently under development include metal oxide semiconductor field-effect transistors (MOSFETs) and insulated gate bipolar transistors (IGBTs).

MOSFET structures could enter the commercial market as soon as 2006 . They em-

Table I: Comparison of Material Properties and Figures of Merit for High-Voltage Switching and High-Frequency Devices.

\begin{tabular}{lrrrr}
\hline \multicolumn{1}{c}{ Property } & Silicon & GaAs & 4H-SiC & GaN \\
Bandgap $(\mathrm{eV})$ & 1.1 & 1.43 & 3.2 & 3.4 \\
Breakdown field $(\mathrm{MV} / \mathrm{cm})$ & 0.6 & 0.65 & 3.5 & 3.5 \\
Saturated electron velocity $\left(\times 10^{7} \mathrm{~cm} / \mathrm{s}\right)$ & 1 & 1 & 2 & 1.5 \\
Bulk electron mobility $\left(\mathrm{cm}^{2} / \mathrm{V} \mathrm{s}\right)$ & 1400 & 8000 & 800 & 900 \\
Combined figure of merit & 1 & 10 & 136 & 153 \\
$\quad$ (normalized to Si) & & & & \\
\hline
\end{tabular}

ploy a native thermally grown oxide layer as the gate insulator, using the same approach that has been successfully used in silicon technology. In the SiC case, however, the making of a perfect $\mathrm{SiO}_{2} /$ semiconductor interface is more difficult than in the case of $\mathrm{SiO}_{2} / \mathrm{Si}$. For one, silicon carbide has two types of atoms and, therefore, two types of potential dangling bonds: carbon and silicon. Second, since the bandgap in the $4 \mathrm{H}$ polytype* of $\mathrm{SiC}$ is $3.2 \mathrm{eV}$ and about three times that of silicon, the states associated with dangling bonds are more likely to induce levels located within the bandgap. The interface charge associated with dangling bonds contributes to the scattering of electrons and low electron mobilities in MOSFETs. A recent breakthrough in postoxidation nitrous oxide annealing reduced the interface charge density to an acceptable level. ${ }^{8}$ A detailed discussion of $\mathrm{SiC} / \mathrm{SiO}_{2}$ interfaces is presented in the article by Dhar et al. in this issue.

Another intriguing intrinsic property of silicon carbide is its high saturated electron velocity $\left(v_{\text {sat }}\right)$. This parameter corresponds to the velocity of electrons traveling through the material in the high electric fields that are encountered in field-effect transistors. It is used to determine the material figure of merit for high-frequency power devices (Table I), as it controls the gain in FETs. It is quite apparent that silicon carbide has significant potential in this field as well. The possible applications range from commercial base stations for cell phones to military $\mathrm{S}$-band radar. It is worth noting that as early as 1996, Westinghouse Electric/CBS demonstrated high-definition TV broadcasting using a solid-state SiC-based transmitter. Cree Inc. has developed and is marketing a range of MESFETs. These devices offer lower loss, higher input and output impedances that are easier to match to antenna impedances, and higher power densities than standard Si- or GaAs-based components. In terms of frequencies, $\mathrm{SiC}$ will likely be used for intermediate-frequency applications, while GaN will work better in high-frequency situations.

In summary, silicon carbide electronics appears to be on the verge of wide commercial production. The material issues are being resolved, multiple device structures

\footnotetext{
* Silicon carbide can crystallize in many different forms, called polytypes, corresponding to different stacking sequences of closely packed planes of atoms. The most commonly used forms of $\mathrm{SiC}$ are $4 \mathrm{H}-\mathrm{SiC}$ and $6 \mathrm{H}-\mathrm{SiC}$, having four or six $\mathrm{Si}-\mathrm{C}$ bilayers in the unit cell, respectively. These are intermediate structures between purely a hexagonal form called $2 \mathrm{H}$ and a cubic form called $3 \mathrm{C}$. The $4 \mathrm{H}$ polytype of $\mathrm{SiC}$ is strongly preferred for silicon carbide electronic devices due to its higher electron mobility compared with $6 \mathrm{H}-\mathrm{SiC}$.
} 
are gaining increasing acceptance in the marketplace, and additional new applications such as high-temperature electronics are waiting to be developed.

\section{References}

1. V. Balakrishna, R.H. Hopkins, G. Augustine, G. Donne, and R.N. Thomas, Inst. Phys. Conf. Ser. 160 (1997) p. 321; J. Giocondi, G.S. Rohreer, M. Skowronski, V. Balakrishna, G. Augustine, H.M. Hobgood, and R.H. Hopkins, J. Cryst. Growth 181 (1997) p. 351; M. Dudley, X.R. Huang,
W. Huang, A. Powell, S. Wang, P. Neudeck, and M. Skowronski, Appl. Phys. Lett. 75 (1999) p. 784. 2. P. Pirouz, Philos. Mag. A 78 (1998) p. 727; T.A. Kuhr, E.K. Sanchez, M. Skowronski, W.M. Vetter and M. Dudley, J. Appl. Phys. 89 (2001) p. 4625. 3. J.P. Bergman, H. Lendenmann, P.A. Nilsson, U. Lindefelt, and P. Skytt, Mater. Sci. Forum 353-356 (2001) p. 299

4. D. Nakamura, I. Gunjishima, S. Yamaguchi, T. Ito, A. Okamoto, H. Kondo, S. Onda, and K Takatori, Nature 430 (2004) p. 1009.

5. H.M. Hobgood, R.C. Glass, G. Augustine, R.H. Hopkins, J.R. Jenny, M. Skowronski, W.C.
Mitchel, and M. Roth, Appl. Phys. Lett. 66 (1995) p. 1364.

6. O. Noblanc, C. Arnodo, C. Dua, E. Chartier, and C. Brylinski, Mater. Sci. Forum 338-342 (2000) p. 1247

7. J.R. Jenny, S.T.G. Mueller, A. Powell, V.F. Tsvetkov, H.M. Hobgood, R.C. Glass, and C.H. Carter Jr., J. Electron. Mater. 31 (2002) p. 366.

8. G.Y. Chung, C.C. Tin, R.J. Williams, K. McDonald, M. Di Ventra, S.T. Pantelides, L.C. Feldmann, and R.A. Weller, Appl. Phys. Lett. 76 (2000) p. 1713
John C. Zolper, Guest Editor for this issue of MRS Bulletin, is the director of the Microsystems Technology Office (MTO) of the U.S. Defense Advanced Research Projects Agency (DARPA). MTO sponsors research in advanced electronics, photonics, MEMS, and integrated microsystems for the Department of Defense. Zolper holds a BA degree in physics from Gettysburg College and a $\mathrm{PhD}$ degree in electrical engineering from the University of Delaware. In 1988, Zolper spent time as a postdoctoral fellow at the University of New South Wales in Sydney, working on high-efficiency silicon solar cells. He then joined Sandia National Laboratories as a senior member of technical staff, where he developed advanced III-V semiconductor processes and devices. In 1997, he was a program officer in the Electronics Division of the Office of Naval Research (ONR), at which time he was responsible for managing the ONR's basic and applied research programs in advanced electronics. His programs included several of the premier academic and industrial teams developing Group III nitride and $\mathrm{SiC}$ electronics.

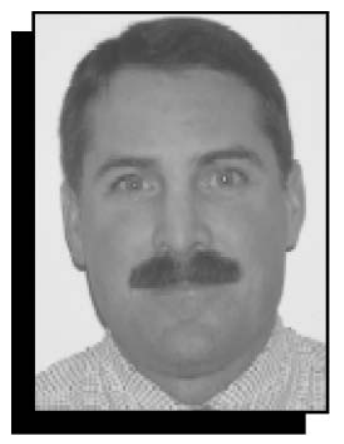

John C. Zolper

He joined DARPA in 2001 as a program manager to initiate a program in wide-bandgap electronics, was appointed deputy director of MTO in 2002, and was made director of MTO in 2005

Zolper is the author or co-author of more than 150 journal articles and conference papers and seven book chapters, and he holds five U.S patents.

Zolper can be reached by e-mail at jzolper@ darpa.mil.

\section{Marek Skowronski, Guest Editor for this issue of MRS Bulletin, has been a professor in the Department of Mate- rials Science and Engi- neering at Carnegie Mellon University since 1988. He received his $\mathrm{PhD}$ degree in solid-state physics from Warsaw University in Poland, after which he was a visiting scientist at the Massachusetts Institute of Technology, working on junction spectroscopy}

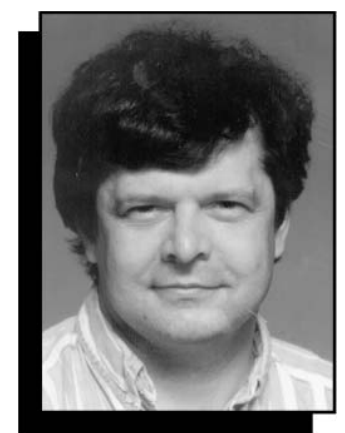

Marek Skowronski

of point defects in GaAs. He then worked as a senior research associate at Cabot Corp., where he studied the growth and characterization of semiinsulating GaAs single crystals.

His current research interests are in crystal growth of wide-bandgap semiconductors and complex oxides, characterization and control of extended and point defects in crystals, and reliability of electronic devices. He is the author or co-author of more than 150 journal articles, conference papers, book chapters, and other publications.

Skowronski can be reached at the Department of Materials Science and Engineering, Carnegie Mellon University, Pittsburgh, PA, 15213 USA; tel. 412-268-2710, fax 412-268-7596, and e-mail ms3s@andrew.cmu.edu.

Scott T. Allen is the RF Engineering Manager at

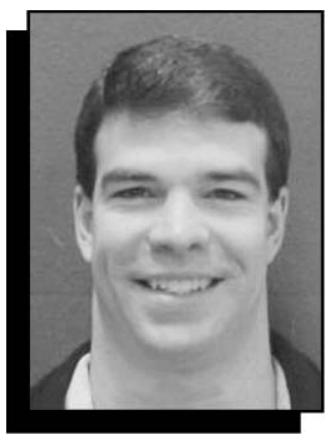

Scott T. Allen

Cree Inc. and has been with the company for more than 10 years. He holds a BS degree from Cornell University; an MS degree from the University of Massachusetts, Amherst; and a PhD degree from the University of California, Santa Barbara, all in electrical engineering. At Cree, he has been involved with the development of all aspects of transistor and MMIC technologies for both SiC MESFETs and GaN devices and is leading the team of scientists and engineers responsible for the development of $\mathrm{SiC}$ and $\mathrm{GaN}$ microwave transistors. He also has experience in MMIC design stemming from his four years as a design engineer at the Lockheed Martin (formerly GE) Electronics Laboratory in Syracuse, N.Y. He holds several issued and pending U.S. patents pertaining to $\mathrm{SiC}$ and GaN device technology.

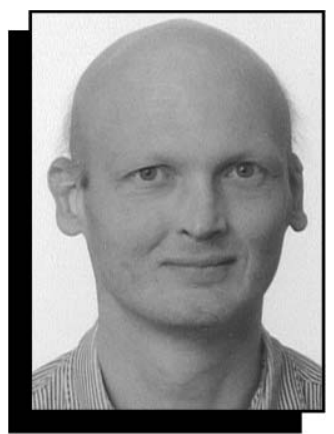

J. Peder Bergman

Allen can be reached by e-mail at scott_allen@ cree.com.

J. Peder Bergman is an associate professor in the Materials Science Group within the Department of Physics and Measurement Technology at Linköping University in Sweden, where he also earned his $\mathrm{PhD}$ degree in 1991. In addition to his university association, Bergman has held joint appointments at $\mathrm{ABB}$ and Okmetic $\mathrm{AB}$. His research activities include structural, electrical, and optical characterization of semiconductor and electronic devices. He is the author or co-author of more than 200 technical publications.

Bergman can be reached at the Department of Physics and Measurement Technology, Linköping University, Linköping, Sweden; tel. 46-13-282382, fax 46-13-142337, and e-mail ped@ifm.liu.se. 
T. Paul Chow is a professor in the Electrical, Computer, and Systems Engineering Department of Rensselaer Polytechnic Institute, where he received his $\mathrm{PhD}$ degree in electrical engineering in 1982.

From 1977 to 1989 , he worked at General Electric Corporate Research and Development, where he developed CVD processes and studied the characterization of doped tin oxide and indium oxide thin films for transparent electrode applications in solid-state imagers, refractory metals, and metal silicides for $\mathrm{Si}$ MOS VLSI applications.

From 1982 to 1989, he participated in research and development for new discrete and integrable MOS-gated unipolar and bipolar devices. He also worked on the process architecture and integration of high-voltage integrated circuits. Chow's present research interests are in developing new device concepts, integrated processes, and circuit models for high-voltage power devices and integrated circuits of silicon and wide-bandgap compound semiconductors. Since 1998, Chow has led the Advanced

Power Semiconductors Thrust for the Center for Power Electronics Systems, an NSF-sponsored Engineering Research Center consortium headed by Virginia Tech.

Chow has published more than 90 papers in refereed scientific journals, presented over 180 conference talks, contributed six chapters in technical textbooks, and holds over ten patents. He received the SolidState Science and Technology Young Author Award from the Electro-

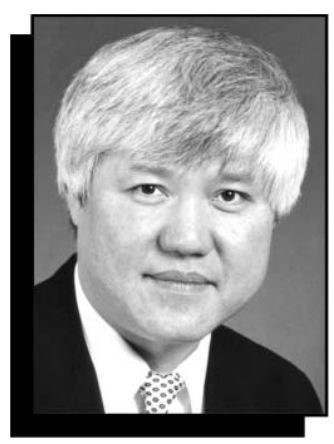

T. Paul Chow

chemical Society in 1982 and the Horizon Award from Augustana College in 1986. He is a senior member of the IEEE and a member of the Electrochemical Society.

Chow can be reached by e-mail at chowt@ rpi.edu.

Sarit Dhar is a PhD student in materials science at Vanderbilt University. He received his MS degree in physics from the Indian Institute of Technology in Kharagpur, India, in 2000. His research focuses on processing and characterization of the $\mathrm{SiO}_{2} / \mathrm{SiC}$ interface for MOS applications.

Dhar can be reached by e-mail at sarit.dhar@ vanderbilt.edu.

Leonard C. Feldman is the Stevenson Professor of Physics and a professor of materials science and engineering at Vanderbilt University. He holds simultaneous positions as a distinguished visiting scientist at Oak Ridge National Laboratory and an adjunct professor of physics at Fisk University. He received his $\mathrm{PhD}$ degree in physics from Rutgers University in 1967.

From 1967 to 1996, he carried out fundamental research and served as a department head at Bell Labs/AT\&T/ Lucent, leading efforts

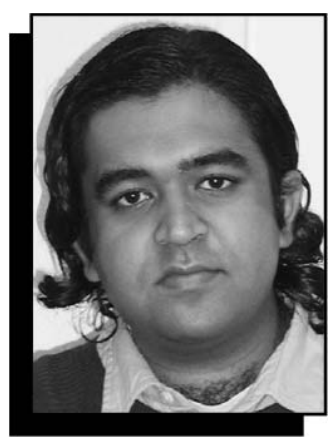

Sarit Dhar

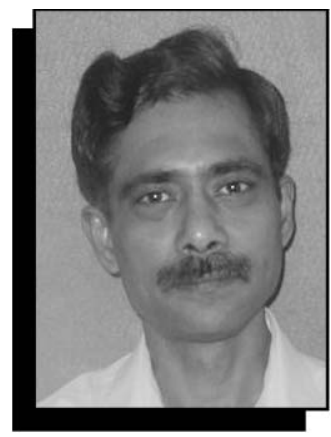

Saptharishi Sriram

in thin-film science, ceramics, radiation physics, and semiconductor materials research, after which he joined Vanderbilt. His research interests focus on the formation and characterization of nanoscale structures and thin films.

Feldman won the 1999 David Adler Lectureship Award from APS. He is a fellow of the American Association for the Advancement of Science, the American Physical Society, and the American Vacuum Society, and was elected to the Royal Danish Academy of Science and Letters. He is the author or co-author of 350 publications and three books on materials physics, and he holds 20 patents.

Feldman can be reached by e-mail at leonard.c.feldman@ vanderbilt.com.

Seoyong $\mathrm{Ha}$ is a senior research engineer at

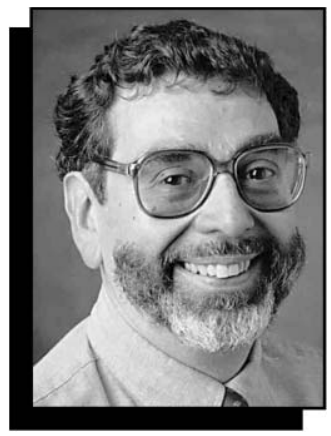

Leonard C. Feldman

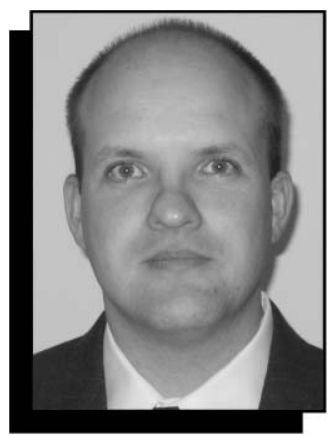

Joseph J. Sumakeris

Samsung Corning Precision Glass in Chungnam, South Korea. He received his BS and MS degrees in metallurgical engineering from Seoul National University. From 1994 to 1997, he worked as a research engineer for LG Cable R\&D Center in South Korea. He earned his $\mathrm{PhD}$ degree from the Department of Materials Science and Engineering at Carnegie Mellon University in 2002. He then accepted a research associate position in the same department, where he focused his research on $\mathrm{SiC}$ crystal growth, characterization of extended defects, and $\mathrm{SiC}$ device reliability. This work was performed in collaboration with $\mathrm{ABB}$ and Cree Inc. He is also an author of more than 20 technical publications.

Ha can be reached at Samsung Corning Precision Glass, 544

Myungam-Ri, TangjungMyun Asan, Chungnam, 336-840, South Korea;

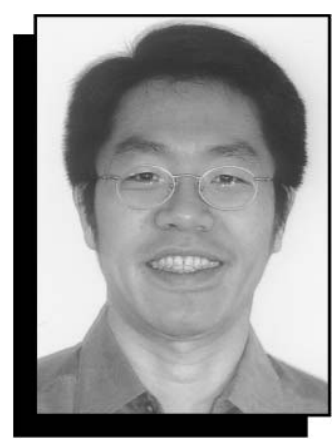

Seoyong $\mathrm{Ha}$

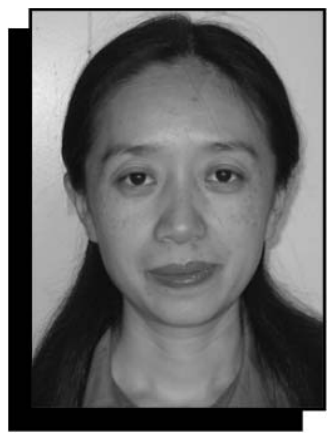

Shurui Wang

tel. 82-41-520-1892 and e-mail seoyong@ gmail.com.

Jason Henning is a device scientist at Cree Inc., where he works on $\mathrm{SiC}$ MESFET and MMIC programs. He received an associate degree in 1986, at which point he began working as an engineering technician at Rockwell Collins Radio, concentrating on antenna designs for radar systems. In 1994, he received a BS degree in electrical engineering from the University of Iowa and worked as a microwave design engineer at Rockwell Collins. In 1995, Henning entered Purdue University, earning an MS degree in electrical engineering in 1997 and a PhD degree in 1999. From 1999 to 2001, Henning was the engineering manager for OptoLynx, a startup company in the Purdue incubator specializing in high-frequency fiber optics. 


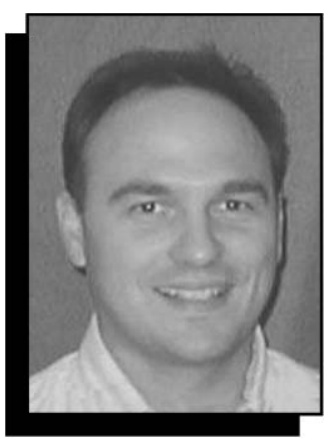

Jason Henning

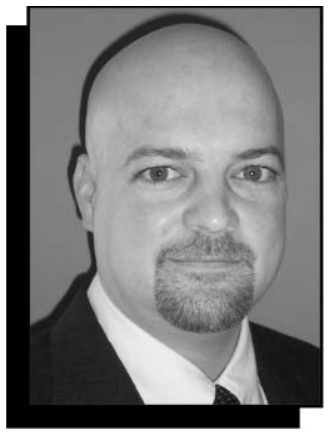

Allan Ward

Henning can be reached by e-mail at jason_henning@cree.com.

Jason R. Jenny is a scientist in the SiC crystal growth group at Cree Inc. He received his $\mathrm{PhD}$ degree in materials science and engineering from Carnegie Mellon University in 1996, where he focused on the characterization of vanadiumdoped SiC. He then worked on an NRC fellowship at WrightPatterson Air Force Base, evaluating Ga desorption during molecular-beam epitaxial growth of GaN materials, accepting his present position in 1997. His current research is directed at understanding the growth and characterization of semiinsulating materials.

Jenny is the author or co-author of more than 35 publications, and he holds three U.S. patents.

Jenny can be reached by e-mail at jason_jenny@ cree.com.

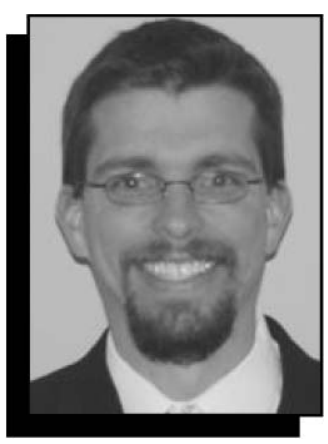

Jason R. Jenny

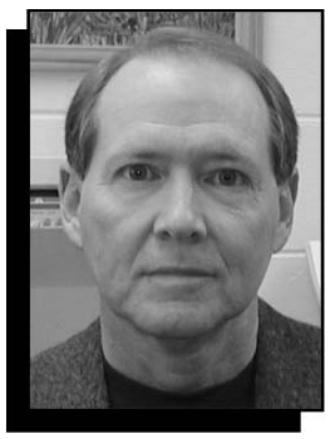

John R. Williams

Sokrates T. Pantelides is the William A. and Nancy F. McMinn Professor of Physics at Vanderbilt University. He also holds an appointment as a distinguished visiting scientist at Oak Ridge National Laboratory. He received his $\mathrm{PhD}$ degree in physics from the University of Illinois at UrbanaChampaign in 1973.

After a postdoctoral appointment at Stanford University, he joined the IBM T.J. Watson Research Center in 1975, where he carried out theoretical research in semiconductors and served as manager, senior manager, and program director. He joined Vanderbilt University in 1994.

His research focuses on the structure, defect dynamics, and electronic properties of electronic materials; radiation effects; transport in molecules and thin films; and catalysis.

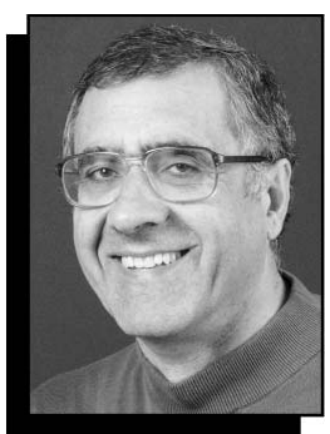

Sokrates T. Pantelides

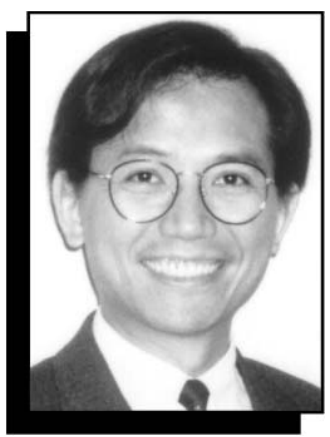

Jian H. Zhao

Pantelides is a fellow of the American Physical Society and the American Association for the Advancement of Science. He is also an author or co-author of 300 research articles and the editor of eight books.

Pantelides can be reached by e-mail at pantelides@vanderbilt. edu.

Adrian R. Powell is a senior research scientist in the SiC crystal growth group at Cree Inc. He earned a $\mathrm{PhD}$ degree in physics from the University of Warwick in 1992 for his doctoral work on the growth and characterization of SiGe.

From 1992 to 1994, he worked at the IBM T.J.

Watson Research Center on molecular-beam epitaxial growth of SiGe and $\mathrm{SiGeC}$ structures on $\mathrm{Si}$. He then joined the $\mathrm{SiC}$ group at ATMI Inc., where he focused on developing 2-in.-diameter $\mathrm{SiC}$ substrates until

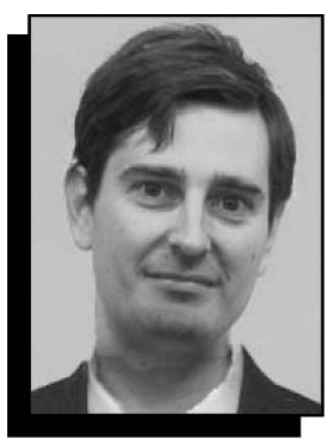

Adrian R. Powell

1999, when he accepted his current position.

His specific research interests include bulk and epitaxial growth of wide-bandgap semiconductors and defect characterization within these materials. He is the author or co-author of over 40 publications and holds three U.S. patents.

Powell can be reached by e-mail at adrian_powell@cree.com.

\section{Saptharishi Sriram} joined Cree Inc. in 2000, where he is responsible for the development of SiC MESFETs for highpower and broadband defense and communications applications. He holds a BE degree in electronics and communication engineering from the Regional Engineering College at the University of Madras in Madras, India, an ME degree in electrical communication engineering from the Indian Institute of Science in Bangalore, and a PhD degree in electrical engineering from the Pennsylvania State University.

From 1975 to 1979 , he was with Bharat Electronics Ltd. in Bangalore, where he worked on CMOS integrated circuits and solar cells. In 1983, he joined Westinghouse Research and Development Center in Pittsburgh (later known as the Science and Tech- nology Center, Electronic Sensors and Systems Sector, of Northrop Grumman Corp.), where he later became an advisory engineer.

He holds seven patents, with six pending in various technical areas.

Sriram can be reached by e-mail at sriram@cree.com.

Joseph J. Sumakeris has been with the $\mathrm{SiC}$ epi group at Cree Inc. since 1995, when he received his PhD degree in materials science and engineering from North Carolina State University.

His primary responsibilities at Cree include epitaxial growth of $\mathrm{SiC}$ for MESFETs, addressing forward-voltage stability in bipolar devices, and developing annealing procedures for implant activation. He is the author or co-author of more than 30 publications, and he holds six U.S. patents.

Sumakeris can be reached by e-mail at joe_sumakeris@cree.com.

Shurui Wang is pursuing research at Auburn University on the $4 \mathrm{H}-\mathrm{SiC} / \mathrm{SiO}_{2}$ interface to enhance the performance of SiC MOSFETs. In 2001, she earned a $\mathrm{PhD}$ degree in semiconductor physics from the Institute of Semiconductors at the Chinese Academy of Sciences. She then completed a year of postdoctoral work on SiC highvoltage devices at Centre de Génie Électrique de Lyon (CEGELY), a laboratory within INSA (Institut National des Sciences Appliquées) in Lyon, France.

Wang can be reached by e-mail at shurui@ physics.auburn.edu. 
Allan Ward is the manager for advanced device reliability at Cree Inc. He holds a BS degree in electrical engineering (1990), an MS degree in materials engineering (1992), and a $\mathrm{PhD}$ in electronic materials science (1996), all from the Virginia Polytechnic Institute and State University.

Between 1993 and 1995, he was with the ITT GaAs Technology Center, working in the area of microwave device reliability. He was then an assistant professor in the Electrical Engineering Department at Virginia Tech, with research interests in power electronic packaging performance and reliability, until 1997.

From then to 1999, he worked as a senior scientist at the Naval Research Laboratory on the reliability of optical microwave systems. Before moving to Cree, he worked for RF Microdevices as the lead scientist for $\mathrm{GaAs}$ device and packaged product reliability.

Ward is currently developing measurement techniques and assessing the reliability of $\mathrm{SiC}$ and $\mathrm{GaN}$ technologies for power electronic and broadband transmission devices.
Ward can be reached by e-mail at allan ward@cree.com.

John R. Williams is the Thomas and Jean Walter Professor in the Physics Department at Auburn University. His research interests include technology development for wide-bandgap semiconductors and materials modification and analysis using $\mathrm{MeV}$ ion accelerators. He is a member of the American Physical Society and the Materials Research Society.

Williams can be reached at the Physics Department, 310 Leach
Science Center, Auburn University, AL 36849 USA; tel. 334-844-4678, fax 334-844-2359, and e-mailwilliams@ physics.auburn.edu.

Jian H. Zhao is a professor of electrical and chemical engineering at Rutgers University, where he heads research on $\mathrm{SiC}$ power and optoelectronic device development at the SiCLAB, the Silicon Carbide Power Device Research Center.

He received his $\mathrm{PhD}$ degree in electrical engineering from Carnegie Mellon University in 1988 with a thesis on
GaAsSb heterostructures grown by MBE. He has been working on photonic and electronic devices based on $\mathrm{SiC}$, $\mathrm{GaN}$, InGaAs, AlGaAs, and $\mathrm{GaAsSb}$, as well as waveguide devices. Together with his students and collaborators, he has published more than 200 papers and book chapters, as well as two books. He holds six U.S. patents on semiconductor devices.

Zhao can be reached by e-mail at jzhao@ ece.rutgers.edu and via the Web at www.ece.rutgers.edu/ $\sim$ zhao.

\section{MRS Materials Connections www.mrs.org/connections/}

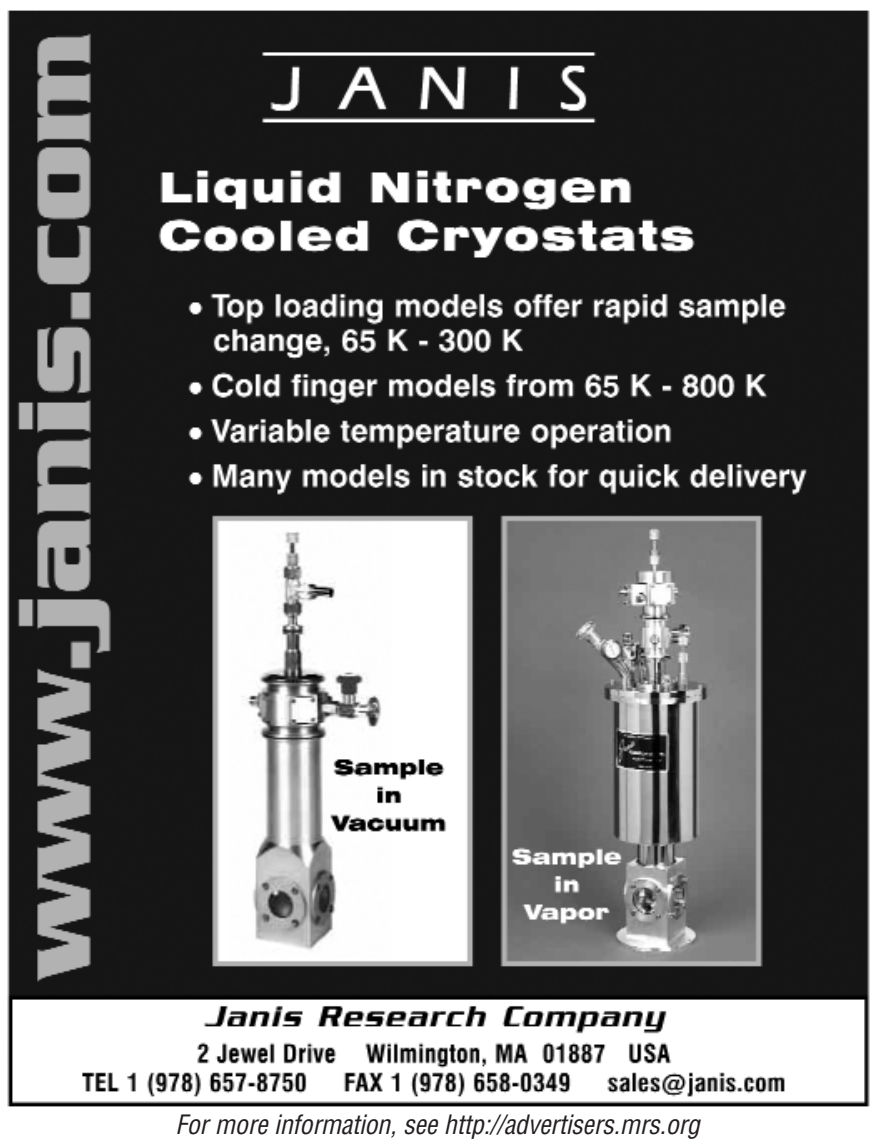

- Top loading models offer rapid sample change, $65 \mathrm{~K}-300 \mathrm{~K}$

- Cold finger models from $65 \mathrm{~K}-800 \mathrm{~K}$

- Variable temperature operation

- Many models in stock for quick delivery

Janis Research Company 6) 657-8750 FAX 1 (978) 658-0349 sales@janis.com

For more information, see http://advertisers.mrs.org

\section{Semi insulating cost effective substrates for high power GaN HEMTs}

2- and 3-inch diameter AIN-on-SiC epi wafers

$\Lambda$ IN thickness: $10 \quad 20$ microns AIN resistivity: $>1 \mathrm{E} 9 \mathrm{Ohm} \mathrm{cm}(300 \mathrm{~K})$ SiC conductivity: n-type

Technologies and Devices International, Inc. 12214 Plum Orchard Dr.Silver Spring, MD, 20904, USA TEL 1 (301) $5727834 \quad$ FAX 1 (301) 5726435 www.tdii.com

For more information, see http://advertisers.mrs.org 